\title{
Seed-producing System in Salvias
}

\author{
Daiichiro Miyajima \\ Faculty of Agriculture, Shinshu University, Kamiinagun, Nagano 399-45, Japan \\ Additional index words. inflorescence, pollination, Salvia splendens
}

\begin{abstract}
The seed-producing system of salvias (Salvia splendens Sello) was investigated. The number of florets opening per day per plant increased with the increase in days from anthesis. Pollinators that effectively worked were small-sized insects. High pollen viability was observed on the stigmatic surface, and pollen tubes reached the ovules within 3 hours after pollination. Fertilized ovules became mature seeds within 25 days after fertilization. Pollination within 1 day after opening of florets resulted in a high percentage of seed setting. The pollen-ovule ratios indicated that salvias were facultative xenogamous. Actually, the salvias had heterostyle florets and the ability to set seeds without pollinators.
\end{abstract}

Seeds of salvias, an important bedding plant, are high priced and often show poor germination in direct seeding (Carpenter, 1989). The seed performance depends highly on the culture methods including the environments in which the seeds are produced (Watkins, 1992). Salvias have long flowering periods, which is an important characteristic of a bedding plant. However, this is not always a favorable characteristic for seed production because the period during which pollinators are active is limited and multiple harvests are inevitable. The objectives of this study were to clarify the seed-producing system in salvias to improve seed-production efficiency. Specifically, the following questions were asked: What is the cumulative number of florets in a given day after anthesis? What kinds of insect pollinate salvias? What is the percentage germination of pollen on stigmatic surfaces? How much time is needed from pollination to fertilization? How many days does an unpollinated pistil stay alive? How does seed set vary during the period between pistil unfolding and pollination? Does seed set differ between self-pollination and outcrossing? Are insects indispensable for seed set? How many pollen grains or seeds does a floret produce? How does a seed grow after fertilization?

\section{Materials and Methods}

This study was done at the farm of the Faculty of Agriculture of Shinshu Univ., Nagano Prefecture, Japan, in 1994. Seeds of 'Little Tango' (dwarf) and 'Tall Purple' (Sakata Seed Corp., Kanagawa) were seeded in a vermiculite medium in polyethylene pots $(15 \mathrm{~cm}$ in diameter and $12 \mathrm{~cm}$ tall) on 17 May 1994. The plants were thinned to one per pot. A $14 \mathrm{~N}-2.2 \mathrm{P}-5.8 \mathrm{~K}$ liquid fertilizer $\left(5 \mathrm{~g} \cdot\right.$ liter $\left.^{-1}\right)$ was applied to the plants once a week after emergence. On 4 July, seedlings of each cultivar were planted in plastic film greenhouses in rows $1.0 \mathrm{~m}$ apart and the distance between seedlings was kept at 0.8 m. A $14 \mathrm{~N}-5.2 \mathrm{P}-11.6 \mathrm{~K}$ coated fertilizer $\left(150 \mathrm{~g} \cdot \mathrm{m}^{-1}\right)$ was broadcast before planting and incorporated into soil. The sides of the greenhouses were opened throughout the study (temperature range, 5 to 35C). 'Little Tango' plants were used for all experiments. 'Tall Purple' plants were used for the daily count of the newly opened florets, pollen counts, and for observing the pollinators.

Floret number. The number of newly opened florets was counted daily in eight plants of each of the two cultivars from anthesis. For the count of the number of shoots, each shoot was counted when at least one floret opened firstly on the shoot. The count ended when the salvias died due to cold temperature. The

Received for publication 18 May 1995. Accepted for publication 2 Jan. 1996. The cost of publishing this paper was defrayed in part by the payment of page charges. Under postal regulations, this paper therefore must be hereby marked advertisement solely to indicate this fact. data on the number of florets opening daily, the cumulative number of shoots, and the cumulative number of florets were fitted to regression equations.

Salvia pollinators. Types of insects which visited salvias and their foraging behavior on florets were observed daily in August and September. The time of day at which the observation was made varied from 0500 to $1700 \mathrm{HR}$. At least $2 \mathrm{~h}$ were used each day.

Pollen-ovule ratio. In August, the number of pollen grains on the anther per floret of 10 florets from 10 separate plants of each cultivar was counted using a microscope (Nikon, Optiphoto; $100 \times$ ), immediately after anther dehiscence, followed by determination of pollen-ovule ratios. Pollen-ovule ratios were compared by the Student's $t$ test between the two cultivars.

Pollen germination on the stigmatic surface. In September, five florets from five salvia plants were pollinated each day with the pollen grains from other salvia plants. To study pollen germination on the stigmatic surface, it is necessary to spread the pollen uniformly on the stigmatic surface without forming clusters (Thomson, 1989). In this experiment, filter papers were torn to make them nappy and the pollinium was touched with the nappy end. Then the pollen grains on the torn filter paper were spread on the stigmatic surface by brushing. Small quantities of pollen grains could be placed onto the stigmatic surfaces without forming clusters by this method. One hour after pollination, florets were picked and the number of pollen grains on the stigmatic surface was counted using a binocular microscope. Pollen grains loading on other pollen grains were not counted. A drop of a solution of $0.1 \%$ aniline blue dissolved in $0.1 \mathrm{~N} \mathrm{~K}_{3} \mathrm{PO}_{4}$ was then placed on the pistil, the pistil was softly squashed under a cover slip and the number of pollen grains germinating was counted using afluorescence microscope $(100 \times$, Olympus, DHS-RFC). Germination percentage of pollen grains was defined as the number of pollen grains germinating per the number of pollen grains on a stigmatic surface $100 \times$. Twenty florets were handpollinated and measured through 4 days.

Time from pollination to fertilization. In September, ray florets were pollinated immediately after opening. Florets were picked at 1h intervals after pollination, their petals removed, and the florets were dipped into 3 ethanol : 1 acetic acid solution. After a few hours of dipping, florets were placed on slides with a few drops of $0.1 \mathrm{~N} \mathrm{~K}_{3} \mathrm{PO}_{4}$ containing $0.1 \%$ aniline blue and were squashed under cover slips. The stained florets were observed for pollen tubes reaching the ovules using a fluorescence microscope. This experiment showed that fertilization occurred between 2 and $3 \mathrm{~h}$ after pollination. In later studies, pollen tube growth was determined at 15-min intervals, 2 to $3 \mathrm{~h}$ after pollination. Five florets were used each time.

Breeding system. In August, salvia plants were treated as follows: 1) hand outcrossing; 2) hand selfing; 3 ) open pollination; 4) covering with mosquito nets (1-mm mesh); and 5) emasculation 
before anther dehiscence. Florets were pollinated and emasculated in the early morning. Ten plants were used for a treatment. Salvia florets are small and easy to break off by touching, so bagging is difficult. Instead of bagging, self-pollinated florets were emasculated immediately after pollination. In a preliminary study, no insect visitation to the emasculated florets occurred. The number of seeds per floret was counted 20 days after treatment. The percentage of florets that set at least one seed in all treated florets, seed-set in all ovules treated, and the mean number of seed per floret (florets with no seeds were excluded) were calculated using the data. Treatments were compared by the chi-square test for independence.

Longevity of unpollinated pistils and variation in seed set with the days from pistil unfolding to pollination. In September, 10 florets from 10 separate plants were emasculated immediately after opening to exclude pollinators' visitation. The longevity of unpollinated pistils was measured by daily observation. Actually, the florets dropped before the pistils died. Therefore, if a floret was found to have dropped, the longevity of the pistil was considered ended. A binocular microscope was used to verify that there were no pollen grains on the stigmas of pistils that had dropped. An additional 20 florets (two florets per plant) were emasculated immediately after opening. Another 10 florets from 10 separate plants were pollinated on the day of their opening. Ten and another ten emasculated florets were pollinated 1 and 2 days after opening, respectively. Seed set was determined 2 weeks after pollination. Seed set and the number of seeds per floret of the florets pollinated 0,1 , and 2 days after opening were analyzed by the chi-square test for independence.

Seed development. In September, florets were pollinated with pollen grains from other plants on the day of their opening. Pollinated florets were tagged. Ovules on the day of floret opening and developing seeds after 1 to 30 days from pollination were measured for length, width, and weight. Ten seeds (ovules) from ten separate florets were measured each day after pollination.

\section{Results and Discussion}

Cumulative number of florets. Anthesis of 'Little Tango' and 'Tall Purple' began in late July and mid-August, respectively. The number of florets opening each day per plant increased quadratically from anthesis for 'Little Tango' (Fig. 1). For 'Tall Purple', it increased up to 20 days after anthesis; then it plateaued up to 50 days after anthesis and began to increase again 50 days after anthesis. For successful seed production, full blooming should synchronize with the season when the temperature for seed set is optimal, the pollina-

Fig. 1. Increase in florets with the days from anthesis in salvias. (top) The number of opening florets per day per plant. Regression equations are $\mathrm{Y}=7.4 \times 10^{-5} \mathrm{X}^{3}+9.7$ $\times 10^{-3} \mathrm{X}^{3}+0.58 \mathrm{X}-0.8, r^{2}=0.41$ for 'Little Tango', $\mathrm{Y}=$ $63 /\left(1+170 \times \mathrm{e}^{-0.37 \mathrm{X}}\right)(\mathrm{X} \leq 49), 0.86$ or $\mathrm{Y}=4.1 \mathrm{X}-139$ $(\mathrm{X} \geq 50), r^{2}=0.27$ for 'Tall Purple'. (middle) Cumulative number of florets per plant. $\mathrm{Y}=0.15 \mathrm{X}^{2}, r^{2}=0.86$ for 'Little Tango', $\mathrm{Y}=0.87 \mathrm{X}^{2}+7 \mathrm{X}, r^{2}=0.86$ for 'Tall Purple'. (bottom) Cumulative number of shoots. $\mathrm{Y}=$ $2.8 \times 10^{-3} \mathrm{X}^{2}, r^{2}=0.85$ for 'Little Tango'. $\mathrm{Y}=0.028 \mathrm{X}^{2}$ $+0.18 \mathrm{X}, r^{2}=0.87$ for 'Tall Purple'. All regression equations are significant at $P=0.01$. tors' activity is high, and the weather is rain-free. Because the number of opening florets per day increased as the days from anthesis increased, a large number of florets are expected to flower in the season good for seed production if seeds are sown early. The cumulative number of florets of a plant is closely associated with the cumulative number of shoots of the plant. The cumulative number of shoots of a plant increased quadratically in both cultivars. The cumulative number of florets of a plant also increased quadratically over time in both cultivars.

Florets totaled 1000 after 80 and 30 days after anthesis in 'Little Tango' and 'Tall Purple', respectively. In salvias, the difference in the cumulative number of florets between dwarf and normal types became large as the days from anthesis increased. As a result, the number of seeds per plant would differ greatly between these types. On the other hand, number of florets should vary somewhat by sowing date because the flowering of salvias is reported to be affected by day length (Crawford, 1960; Lai and Weiler, 1975; Weiler, 1972; Weiler and Lai, 1973).

Salvia pollinators. Several kinds of insects and hummingbirds are reported as pollinators for salvias (Grant and Grant, 1964). The study concluded that small-sized bees are effective pollinators for salvias. In Salvia splendens, pollinators are obliged to creep into narrow tubes to collect nectar or to hang on the florets to collect pollen because pollinia face downward and the corolla is overhanging on the anthers. In these studies, Halictus aerarius (length, 5-6 mm) was observed to visit salvias most frequently throughout the anthesis. This insect species collected pollen grains or nectar
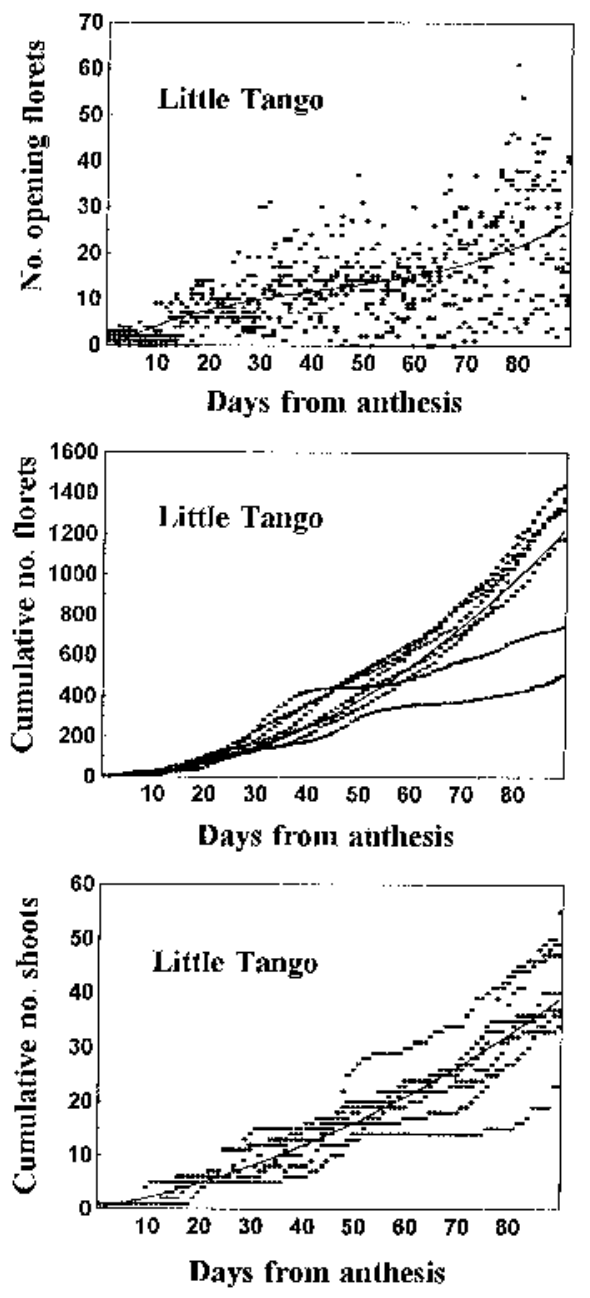
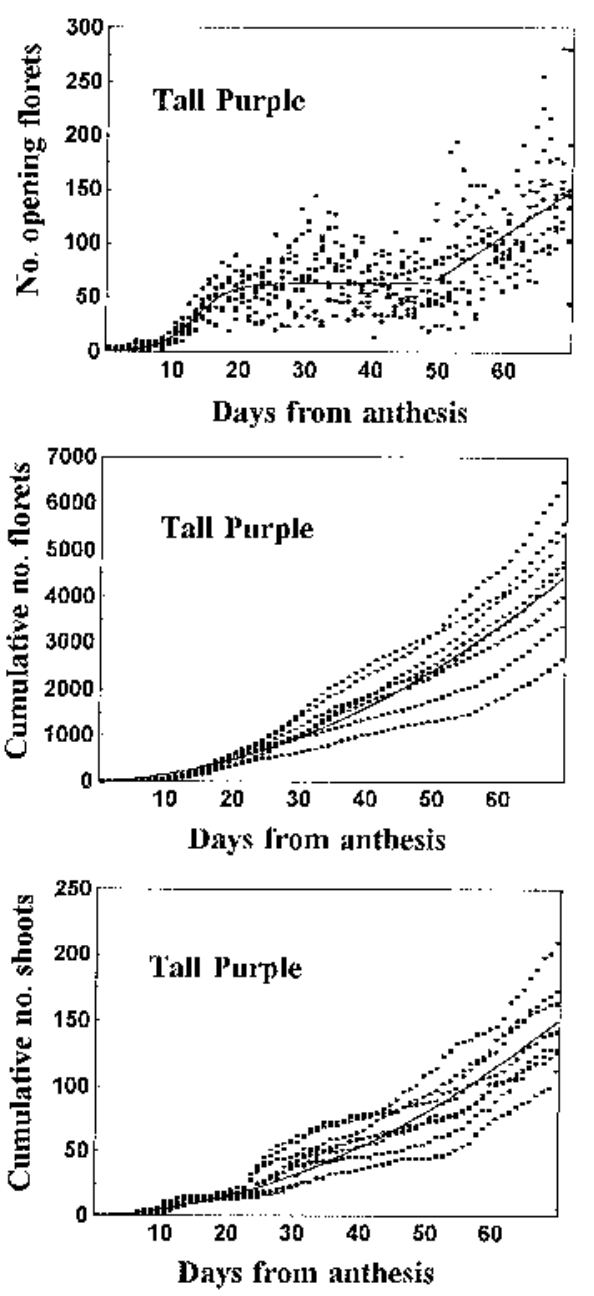
Table 1. Sed set of salvias subjected to five breeding conditions.

\begin{tabular}{lccc}
\hline \hline Treatment & $\begin{array}{c}\text { Florets with } \\
\text { mature seeds }(\%)\end{array}$ & $\begin{array}{c}\text { Mature seeds/ } \\
\text { ovules (\%) }\end{array}$ & $\begin{array}{c}\text { Mature seeds/ } \\
\text { floret }^{2} \text { (no.) }\end{array}$ \\
\hline Outcross & $59 \mathrm{a}^{\mathrm{y}}$ & $36 \mathrm{a}$ & 2.4 \\
Self & $52 \mathrm{a}$ & $30 \mathrm{~b}$ & 2.3 \\
Open pollination & $46 \mathrm{~b}$ & $29 \mathrm{~b}$ & 2.5 \\
Mosquito net cover & $32 \mathrm{c}$ & $19 \mathrm{c}$ & 2.4 \\
Emasculation & $0 \mathrm{~d}$ & $0 \mathrm{~d}$ & --- \\
\hline
\end{tabular}

${ }^{\mathrm{z}}$ Florets with no mature seeds are not included.

${ }^{\mathrm{y}}$ Mean separation by chi-square test for independence at $P=0.05$.

hanging from the stamens or creeping into corolla tubes. Another major insect species which visited salvias was Melanostoma mellinum (length, 6-7 mm). Several Syrphidae observed, all <10 $\mathrm{mm}$, fed on pollen exclusively. Thus, the frequent visitors were small-sized insects. In 1994, Apis mellifera (honeybee) and Polistes chinensis were observed to access salvias, but foraging behavior was not observed. They flew away without collection of rewards. In 1995, foraging of honeybees was observed. They hung onto the edge of corolla tubes and collected pollen. For foraging for nectar, honeybees crept into the tubes, but became lodged in the middle of the tubes and struggled, then they crept out of the tubes. How much nectar they collected was not clear. Throughout the anthesis of salvias, the visit of honeybees was rare in contrast to the frequent foraging to zinnias in the same field. Eristalomyia tenax, which visited zinnias frequently, were not observed around salvias. A few Vespidae fed on nectar from fallen florets or by holing the base of tubes from the outside. They did not contribute to pollination. The kinds of pollinators of a given plant species are associated with its morphology (van der Pijl, 1961), that is, in addition to the components of nectar (Butler, 1945; Vansell, 1934), the visits of pollinators depends on the ease of obtaining rewards. In Salvia splendens, the smaller the size of the pollinators, the easier the foraging behavior is because of the morphology of the florets. In these studies, observation indicated that small-sized insects were effective pollinators for Salvia splendens.

Pollen-ovule ratio. The pollen-ovule ratios were $2340 \pm 190$ (mean \pm confidence limit at the $95 \%$ level) and $3120 \pm 360$ for 'Little Tango' and 'Tall Purple', respectively. According to the classification by Cruden (1977), this ratio is classified within xenogamy but not as high as xenogamy. Therefore, combination with the self-pollination system was feasible.

Pollen germination on the stigmatic surface. Pollen of salvias did not germinate on media of several combinations of agar, gelatin, sucrose, and $\mathrm{Na}_{2} \mathrm{~B}_{4} \mathrm{O}_{7} \bullet 10 \mathrm{H}_{2} \mathrm{O}$ (data not shown). The germination percentage on the stigmatic surface was determined to be $76 \%$ (the upper and lower confidence limits were $86 \%$ and $66 \%$, respectively). In the present experiment, a small amount of pollen grains was attached to the stigmatic surfaces without forming clusters. Generally, germination of pollen grains is enhanced when many pollen grains are present on a stigma (Kearns and Inouye, 1993). The result indicated that a large pollen load on a stigma is not necessary for a floret to set seed.

Time from pollination to fertilization. Pollen tubes reached ovules 135 to $150 \mathrm{~min}$ after pollination; thus fertilization probably occurred within $3 \mathrm{~h}$ from pollination.

Breeding system. Seed-set of the emasculated florets was $0 \%$ (Table 1). Therefore, pollination by wind was negligible. Emasculation was adequate as a substitute for bagging to exclude pollinators' visitation. Seed set in plants pollinated indicated that salvias were homogamous. The percentage of florets which set at least one seed in all florets treated was not significantly different between self-pollination and outcrossing. This result indicated that salvias do not have a self-incompatibility system. On the other hand, seed set in all ovules treated was less with self-pollinated florets than with those outcrossed. The percentage of florets that set at least one seed in all florets treated was less with open-pollinated florets than with those hand-pollinated. Generally, pollinators' visitations for salvias were not so frequent. More than $30 \%$ of florets set at least one seed in plants covered by mosquito nets. The salvias used here were heterostylous with long-styled and medium-length-styled florets (Fig. 2). The medium-length-styled florets self-pollinated automatically because the stigmas touched the anthers easily. Plants under mosquito nets probably produced seeds by this system. Plants control outcrossing rate by various methods (Dafni, 1992). In a wild Labiatae, the outcrossing rate is controlled by a combination of cleistgamy and chasmogamy (Lord, 1979). The cultivars used in the present experiment controlled outcrossing rate by heterostyly.

Longevity of unpollinated pistils and variation in seed set with the days from pistil unfolding to pollination. Unpollinated florets were found to have fallen 3 days after opening. Therefore, florets were hand-pollinated 0,1 , and 2 days after opening. The percentage of florets that set at least one seed and seed set in all ovules was not different between florets pollinated 0 and 1 day after opening, but seed set decreased for florets pollinated 2 days after opening (Table 2 ). Because the period in which salvia florets can receive pollen was short, successive rainfall or a low temperature regime, in which pollinators' activity is low, would greatly affect seed production.

Seed development. Embryo length of salvias increased rapidly up to 5 days after pollination (Fig. 3). From 16 days after pollination, embryo length decreased on account of the desiccation due to

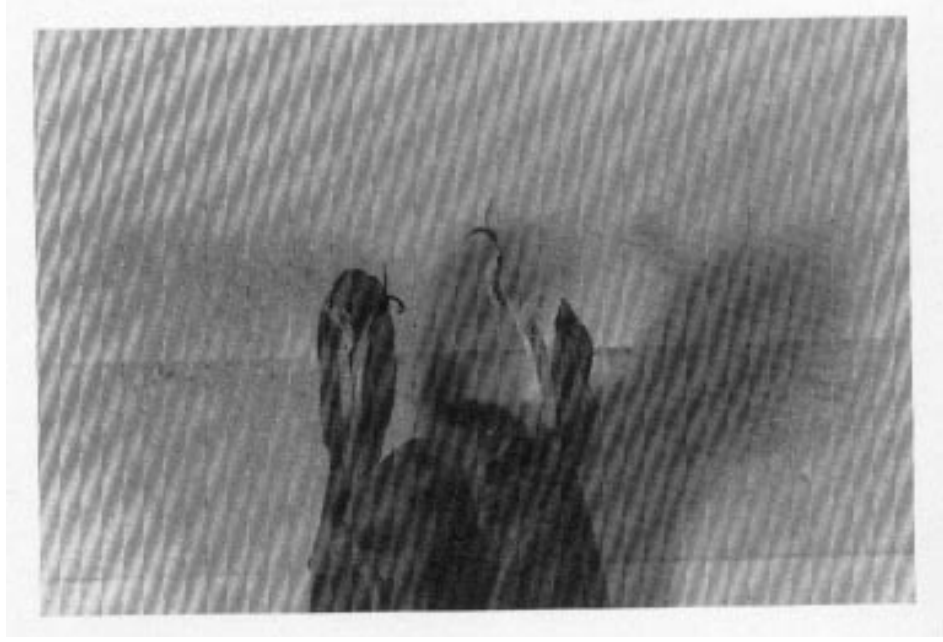

Fig. 2. Heterostyly in salvias. (left) A medium-length styled floret. It self-pollinates easily by brushing. (right) A long-styled floret; pollinators are indispensible for pollination. 
Table 2. Effects of days from floret opening to pollination on seed set of salvias.

\begin{tabular}{lccc}
\hline \hline $\begin{array}{l}\text { Days from floret } \\
\text { opening to polination }\end{array}$ & $\begin{array}{c}\text { Flortes with } \\
\text { mature seeds (\%) }\end{array}$ & $\begin{array}{c}\text { Mature seeds/ } \\
\text { ovules (\%) }\end{array}$ & $\begin{array}{c}\text { MAture seeds/ } \\
\text { floret (no.) }\end{array}$ \\
\hline 0 & $59 \mathrm{a}$ & $36 \mathrm{a}$ & 2.4 \\
1 & $62 \mathrm{a}$ & $37 \mathrm{a}$ & $2.4^{\text {NS }}$ \\
2 & $25 \mathrm{~b}$ & $17 \mathrm{~b}$ & 2.7 \\
\hline
\end{tabular}

${ }^{\mathrm{z}}$ Florets with no mature seeds are not included.

y Mean separation by chi-square test for independence at $P=0.05$.

${ }^{\mathrm{N}}$ Nonsignificant.

maturing (Bewley and Black, 1985). Embryo width and embryo weight increased up to 7 days after pollination. They decreased from 21 days after pollination. Pericarp color remained white until about 20 days after pollination followed by alteration to partial dark brown. Pericarps of seeds 22 days after pollination were wholly dark brown. With the alteration of pericarp color to the dark brown, seeds became easily detachable from receptacles resulting
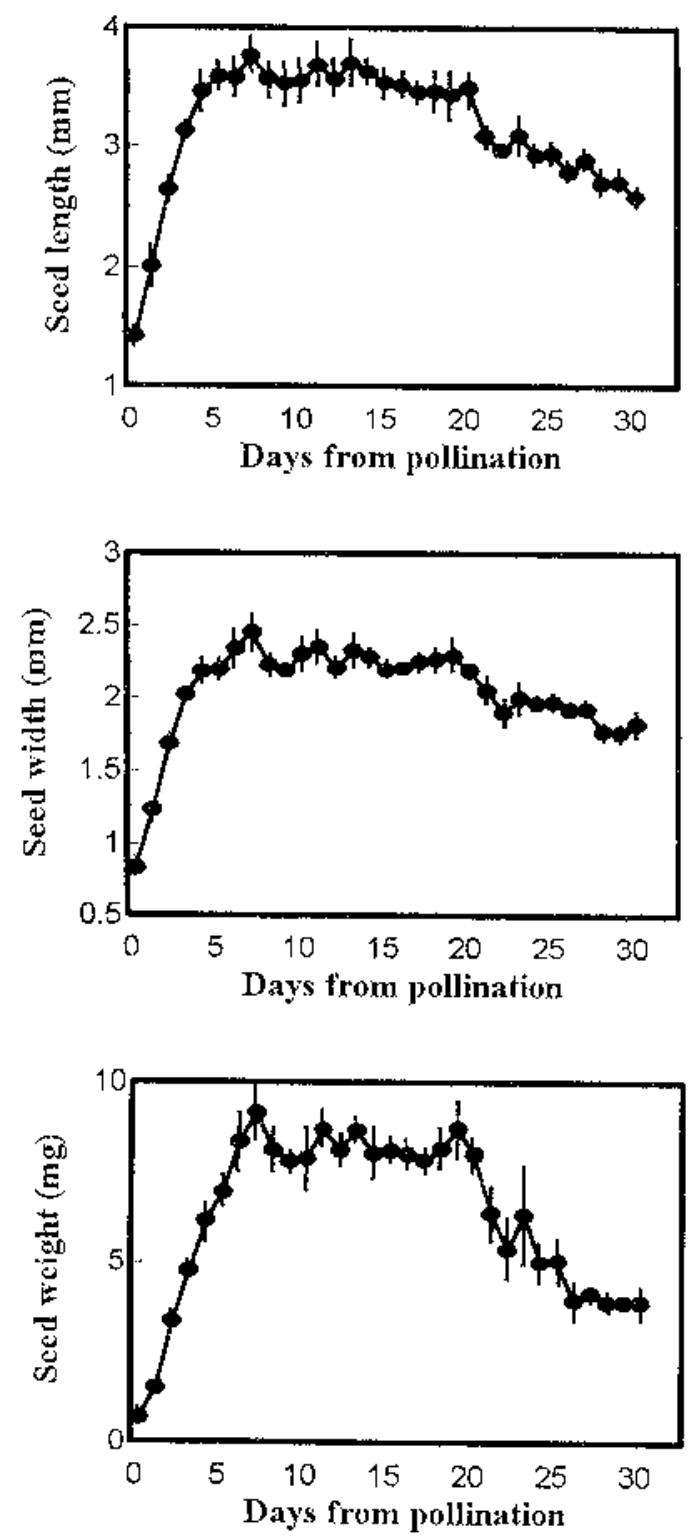

Fig. 3. Development of seeds in salvia 'Little Tango'. (top) Increase in seed length. (middle) Increase in seed width. (bottom) Increase in seed weight. Vertical bars denote confidence limits at the $95 \%$ level. in seed drop. The longer the period from pollination, the more frequent was the drop. Therefore, optimal harvest time was considered to be 22 to 25 days after pollination.

\section{Conclusions}

In salvias, the number of opening florets per day increased with the increase in the days from anthesis. Small-sized insects were effective pollinators. Pollen viability on the stigmatic surface was high. Fertilization occurred within $3 \mathrm{~h}$ after pollination. Florets can be pollinated during the first 2 days after opening to set seeds, but pollination within 1 day after opening is the best. Fertilized ovules developed to mature seeds within 25 days after fertilization. The pollen-ovule ratios indicate that the two cultivars used in the present study were facultative xenogamous. The amount of pollen grains in a floret is not as large for the seed production by xenogamy only; a combination with self-pollination was indispensable. Apart from the maintenance of the diversity of genes, it is necessary to breed salvias that produce seeds easily, e.g., cultivars with the majority of autogamous medium-length-styled florets.

\section{Literature Cited}

Butler, C.G. 1945. Influence of various physical and biological factors of the environment on honeybee activity. An examination of the relationship between activity and nectar concentration and abundance. J. Expt. Biol. 21:5-12.

Bewley, J.D. and M. Black. 1985. Seed development and maturation, p. 70-74. In: Seeds. Plenum, New York

Carpenter, W.J. 1989. Salvia splendens seed pregermination and priming for rapid and uniform plant emergence. J. Amer. Soc. Hort. Sci. 114:247-250.

Crawford, R.M.M. 1961. The photoperiodic reaction in relation to development in Salvia splendens. Ann. Bot. ns 25:78-84.

Cruden, R.W. 1977. Pollen ovule ratios: A conservative indicator of breeding systems in flowering plants. Evolution 31:32-46.

Dafni, A. 1992. Pollination ecology. Oxford Univ. Press, New York.

Grant, K.A. and V. Grant. 1964. Mechanical isolation of Salvia apiana and Salvia mellifera (Labiatae). Evolution 18:196-212.

Kearns, C.A. and D.W. Inouye. 1993. Pollen, p. 77-151. In: Techniques for pollination biologists. Colorado Univ. Press, Niwot.

Lai, C.H. and T.C. Weiler. 1975. Juvenility and photoperiod-dependent inflorescence development of Salvia splendens Sello. J. Amer. Soc. Hort. Sci. 100:438440.

Lord, E.M. 1979. Intra-inflorescence variability in pollen/ovule ratios in the cleistogamous species Lamium amplexicaule (Labiatae). Amer. J. Bot. 67:529533.

Pijl, L. van der. 1961. Ecological aspects of flower evolution. II. Zoophilous flower classes. Evolution 15:44-59.

Thomson, J.D. 1989. Germination schedules of pollen grains: Implications for pollen selection. Evolution 43:220-223.

Vansell, G.H. 1934. Relation between the nectar concentration in fruit blossoms and the visits of honeybees. J. Econ. Entomol. 27:943-945.

Watkins, J.T. 1992. The effect of environment and culture on vegetable seed quality. HortTechnology 2:333-334.

Weiler, T.C. 1972. The variable flowering response of Salvia splendens Sello to daylength. J. Amer. Soc. Hort. Sci. 97:355-357.

Weiler, T.C. and C.H. Lai. 1973. Critical daylength for inflorescence formation of several cultivars of Salvia splendens Sello. HortScience 8:184. 